\title{
POSSÍVEIS IMPACTOS EDUCACIONAIS DOS JOGOS DIGITAIS NO ESTUDO DA LÍNGUA INGLESA
}

\author{
POSSIBLE EDUCATIONAL IMPACTS OF DIGITAL GAMES IN THE STUDY OF \\ ENGLISH LANGUAGE
}

DOI: $10.23926 /$ RPD.2526-2149.2020.v5.n2.p782-800.id744

\section{Wálisson Dias Pinto \\ Especialista de Tradução \\ Português-Inglês/Inglês- \\ Português (UGF) \\ Professor no Centro \\ Universitário de Formiga \\ (UNIFOR-MG) \\ lalinhodias@hotmail.com}

\section{Cláudio Alves Pereira}

Doutorando em Educação

(UFES)

Professor no curso de Pós-

Graduação em Docência no

IFMG Campus Avançado

Arcos

claudioapessoal@gmail.com
Resumo: Os jogos digitais são tidos como entretenimento popular entre jovens e adultos. Este trabalho objetiva identificar as suas potencialidades em contribuir para a aprendizagem dos conteúdos escolares, mais especificamente da Língua Inglesa, idioma predominante no mercado desses jogos. Os dados foram coletados por meio de um estudo investigativo utilizando questionário eletrônico enviado a estudantes da Educação Básica e do Ensino Superior. As respostas dos 114 participantes foram analisadas tendo o paradigma qualitativo como norteador. Os resultados apontam que, embora os conhecimentos da Língua Inglesa aprendidos em sala de aula tenham sido importantes para a ambientação nos jogos, a maioria dos respondentes $(83,5 \%)$ confirma ter aprofundado as habilidades do idioma inglês por meio dessa prática. Este estudo aponta que esta imersão contribui significativamente para a aprendizagem da língua inglesa. Conclui-se que os jogos digitais se constituem como importantes ferramentas auxiliares para os professores de Língua Inglesa organizarem a sua prática pedagógica. Palavras-chave: Jogos Digitais. Língua Inglesa. Aprendizagem Tangencial.

\begin{abstract}
Digital games are seen as an popular entertainment among young people and adults. This paper aims to identify their potential to contribute to the learning of school content, more specifically the English language, which is the predominant language in these game's market. The data were collected through an investigative study using an electronic questionnaire sent to students of Basic and Higher Education. The responses of 114 participants were analyzed using the qualitative paradigm as a guide. The results show that, although the knowledge of the English language learned in the classroom was important for the setting in the games, the majority of respondents $(83.5 \%)$ confirm that they have deepened their English skills through this practice. This study points out that this immersion can contribute significantly to the learning of the English language. It is concluded that digital games are important auxiliary tools for teachers of English language to organize their pedagogical practice.
\end{abstract}

Keywords: Digital Games. English Language. Tangential Learning. 


\section{INTRODUÇÃO}

A prática dos jogos digitais tem aumentado nos últimos anos e, com o suporte de tecnologias cada vez mais aprimoradas, passou-se a explorar enredos mais complexos, cenários mais ricos em detalhes e uma fascinante proximidade com a realidade, aumentando a imersão do jogador com o ambiente apresentado pelo mundo virtual apresentado no jogo. Tendo em vista esse cenário, o presente artigo parte da hipótese de que o ambiente dos jogos digitais, pela atratividade que vem demonstrando entre os estudantes jovens e adultos, permite reforçar o que é aprendido na educação formal (bem como reformulações e contestações) e ainda apresentar informações adicionais, sendo estas diluídas em sensações diversas que aguçam a fala, a audição e a visão dos jogadores.

Pelas restrições impostas para a escrita de um artigo e o aprofundamento permitido pelos limites de páginas, focaremos na investigação das possíveis contribuições dos jogos digitais para a aprendizagem da Língua Inglesa. Como a maior parte dos jogos digitais chega ao Brasil nesse idioma, a imersão do jogador acontece naturalmente; estimulado, o participante se vê obrigado a pesquisar termos apresentados na tela do jogo escritos no idioma inglês. Conforme estudos de Vygotsky (1993), que defende que a interação é o principal gatilho para a aprendizagem, a pesquisa busca estabelecer uma relação entre os jogos digitais e o ensino da Língua Inglesa.

Buscou-se investigar junto aos sujeitos praticantes dos jogos digitais, estudantes da educação básica e superior, como eles constroem o conhecimento a partir das possibilidades oferecidas nos jogos digitais, a partir das interações entre eles e o ambiente dos jogos e com os outros jogadores. Adotou-se o paradigma qualitativo para a análise dos dados e estes foram organizados de maneira a focar no possível desenvolvimento das quatro habilidades fundamentais para a aprendizagem de um idioma: leitura, escrita, fala e audição.

Nas análises elaboradas pelos pesquisadores, intendeu-se problematizar a possibilidade da inserção dos jogos digitais nos ambientes escolares, entendendo-os como elementos culturais de presença no cotidiano de uma parcela da população dos estudantes. Durante as análises, os dados também identificaram a motivação do estudante pela busca de conhecimento estimulada pela interação no ambiente dos jogos digitais. Ao identificar elementos que possibilitem o desenvolvimento de habilidades e competências na interação com os games, notadamente no estudo da Língua Inglesa, esse estudo busca apresentar subsídios para que os professores avaliem a possibilidade de terem essas ferramentas como auxiliares em sua prática pedagógica cotidiana. 


\title{
2 OS JOGOS DIGITAIS E O APRENDIZADO NA LÍNGUA INGLESA
}

Atualmente, os jogos digitais são formas de entretenimento populares no mercado, competindo em igualdade com outras formas de mídias como o cinema, a televisão e a música. Dados da NPD Groups ${ }^{1}$ indicam que $63 \%$ da população dos Estados Unidos jogam videogames e que cerca de $91 \%$ das crianças entre 2 e 17 anos têm os jogos digitais como uma prática habitual. No Brasil, segundo dados da $\mathrm{PGB}^{2}, 66,3 \%$ dos jovens brasileiros jogam games eletrônicos, sendo o smartphone $(83 \%)$ e o videogame $(48,5 \%)$ os meios mais utilizados para esta prática.

Atentos ao aumento do uso de jogos digitais por parte de jovens em idade escolar, alguns estudos têm se empenhado em investigar possíveis relações entre a prática desses jogos e os impactos no processo educacional desses indivíduos. Alguns desses estudos tratam, inclusive, do uso dos jogos digitais como ferramentas de aprendizagem.

Brincher e Silva (2012) elenca alguns pontos positivos e negativos no processo de inserção dos jogos digitais no ambiente educacional. Como pontos positivos, o autor cita i) a profusão cada vez maior de títulos, plataformas, gêneros, modos de jogabilidade e convergência de mídias; ii) a popularidade dos jogos entre diferentes faixas etárias; e iii) as crescentes iniciativas de produção de jogos para fins educacionais. Ao invés de serem vistos pela Escola como meros distrativos (uma das dificuldades de se implantar a prática dos jogos no ambiente escolar), o autor apresenta outras questões que interferem nas propostas de implantação destas tecnologias no planejamento das atividades acadêmicas pelo professor:

\begin{abstract}
Os jogos ofertados atendem à demanda dos professores e à demanda de um componente curricular específico? As instituições educacionais possuem condições técnicas e recursos humanos capacitados para tal? O aparente descompasso entre gerações - o professor nem sempre é ou foi um jogador e, por isso, sua familiaridade com esse universo é meramente tangencial - configuraria impedimento para a efetiva implementação de uma proposta dessa natureza? Como escolher - e onde obter - os jogos necessários a diferentes objetivos educacionais? (BRINCHER; SILVA, 2012, p. 42).
\end{abstract}

Vygotsky (1993) afirma que uma das formas mais eficientes de se obter sucesso no processo de ensino-aprendizagem é por meio da interação. Para ele, "o conhecimento é o produto da interação entre a pessoa e o meio, mas o meio entendido como algo social e cultural,

\footnotetext{
${ }^{1}$ The Video Game Industry Is Adding 2-17 Year-Old Gamers At A Rate Higher Than That Age Groups Population Growth. Disponível em: http://www.npd.com/wps/portal/npd/us/news/pressre leases/pr_111011. Acesso em 19 abr. 2020.

2 Pesquisa Gamer Brasil, 2019. Comportamento, consumo e tendências do gamer na América Latina. Disponível em: https://www.pesquisagamebrasil.com.br/pesquisa-game-brasil-2019/. Acesso em 26 abr. 2020.
} 
não apenas físico" (p.59). Ainda que o autor tenha desenvolvido os seus estudos em uma época em que não existiam esse tipo de mídia, podemos nos alinhar a ele e afirmar que os jogos digitais criam um ambiente social e cultural em que se observa um processo interacional entre o ambiente virtual e o jogador.

Smolka e Góes (1998) também trazem contribuições importantes para a questão da aprendizagem sociocultural (conceito cunhado por Vygotsky):

\section{[...] o processo de conhecimento é concebido como produção simbólica e material que tem lugar na dinâmica interativa. Tal movimento interativo não está circunscrito apenas a uma relação direta sujeito-objeto, mas implica, necessariamente, uma relação sujeito-sujeito-objeto. Isso significa dizer que é através de outros que o sujeito estabelece relações com objetos de conhecimento, ou seja, que a elaboração cognitiva se funda na relação com o outro (SMOLKA; GÓES, 1998, p.9).}

Há uma literatura significativa sobre como os jogos digitais podem influenciar na aprendizagem dos alunos. Por meio da prática dos jogos, o aluno pode conseguir imergir em um outro patamar, além da sala de aula, e, com isso, pode conseguir dar certa praticidade ao conteúdo aprendido, ou seja, extrapolar os termos teóricos e conseguir encontrar relações práticas para o que é estudado no ambiente escolar. O aluno deixa de ser apenas um ouvinte e passa a ser o centro da aprendizagem ativa, baseada em problemas, que fornece feedback imediato, consistente com teorias educativas, ao estudante quanto seus acertos e erros. (CONNOLLY et al., 2012). Segundo os mesmos autores, o aluno ainda pode compartilhar suas conquistas e, com isso, se sente motivado a progredir cada vez mais.

Fleury; Nakano e Cordeiro (2014) defendem o crescimento desses jogos em várias possibilidades de uso (para além do entretenimento) e os seus usos como mediadores do conhecimento. Essas discussões vêm crescendo de forma significativa no cenário nacional e internacional, apontando dados de que esta mediação tem potencial para promover o desenvolvimento de habilidades cognitivas, sociais, afetivas, motoras, dentre outras, em diferentes áreas, especialmente na Educação e na Saúde. Os autores ainda apontam que esse crescimento pode ser constatado através dos relatórios oficiais financiados pelo Banco Nacional de Desenvolvimento Econômico e Social (BNDES), que indicam também o crescimento das vendas e a popularização dos smartphones contribuindo para a produção de jogos, simuladores e aplicativos gamificados, incluindo tanto para jogadores com mais experiência, como para jogadores iniciantes, inclusive mulheres (FLEURY; NAKANO; CORDEIRO, 2014).

Conforme também aponta Gonçalves (2016), inicialmente não havia a necessidade de os jogos serem traduzidos, pois eram muito intuitivos, com narrativas simples e com poucos textos. Contudo, com o passar do tempo e a evolução tecnológica nos jogos, as narrativas 
ficaram mais complexas a ponto de eles virarem uma espécie de filme. Ainda sobre a expansão da necessidade desta tradução, a autora destaca:

Esse campo relativamente recente, comparado a outros como a literatura e o cinema, ganha cada vez mais espaço, uma vez que o Brasil é o país com maior possibilidade de expansão no mercado (...). Assim, temos uma grande gama de jogos que já são distribuídos com as opções dublados ou legendados, tal como são os DVDs distribuídos nacionalmente. (GONÇALVES, 2016, p. 12)

Porém, em casos em que os jogos não possuem a opção de serem jogados no idioma português, o aluno precisa contar com as habilidades desenvolvidas durante sua formação escolar, ou ir aprendendo de maneira passiva através de sua prática. Lima, Souza e Luquetti (2014) apresenta aspectos que são difíceis de se trabalhar em língua inglesa dentro de sala de aula, como a audição e a fala por exemplo, exatamente pelo fato de o discente não ter onde encontrar esse tipo de fonte. Já Centenaro (2016) demonstra como os professores podem utilizar desse contexto educacional dos alunos para aprimorar o ensino da língua inglesa em sala de aula, explorando os discursos e temas apresentados pelos jogos, utilizando a pedagogia de gêneros e multiletramentos.

Koster (2005) associa a diversão ligada aos desafios que um jogo digital proporciona, estabelecendo o desejo implícito do jogador em ser desafiado pelo jogo e progredir em suas fases e, ao mesmo tempo, ao desafio imposto aos criadores dos jogos em manter o jogador sempre motivado. Segundo ele, “...um jogo deixa de ser divertido quando deixa de desafiar o jogador, ou seja, quando este o domina profundamente. (...) Quando um jogo deixa de nos ensinar, ficamos entediados. O tédio é o cérebro buscando novas informações”. (p.42).

Nesse paralelo, focaremos na chamada aprendizagem tangencial. Nesse processo, “o aluno tem contato com o conhecimento sem perceber a intenção de ensiná-lo" (LEITE, 2015, p. 135) e o processo de aprendizagem, embora não aconteça no ato de jogar, o jogo apresenta ao sujeito elementos sensoriais (visuais, auditivos, dentre outros) que desperta-lhe o interesse para determinada área ou assunto. Estando situado em um ambiente virtual que simula algum aspecto da realidade e através de suas interações no ato de jogar, o jogador acaba desenvolvendo habilidades e absorvendo certos conceitos, automaticamente. Conforme exemplifica Shaffer et al. (2005, apud PENICHEIRO, 2014, p. 28), "os jogos digitais potencializam oportunidades de 'experimentação' sobre o fenômeno modelado (...) promovendo uma problematização contextualizada e enriquecendo o tipo de compreensão sobre os fenômenos complexos de história". 
Desta forma, usando desta base teórica, este estudo procura identificar como o aluno pode desenvolver essa aprendizagem tangencial por meio dos jogos digitais. De acordo com Breuer e Bente (2010), esse conceito de aprendizagem é promissor para promover mais aprendizado autodirigido e proativo. Consequentemente, entendemos que os jogos digitais podem ser ferramentas importantes no auxílio ao professor no processo de aprendizagem, elementos motivadores e geradores de curiosidade.

\section{Procedimentos metodológicos}

Para desenvolver este trabalho, foi realizada uma revisão bibliográfica com alguns autores que já debateram sobre o potencial dos jogos digitais no processo de ensinoaprendizagem na educação formal. Discutidas as possibilidades de levantamento dos dados, os pesquisadores decidiram construir um formulário eletrônico direcionado a estudantes tanto da Educação Básica quanto do Ensino Superior; as pré-categorias foram formuladas e as questões elaboradas para que os dados pudessem evidenciar como os jogadores analisam sua aprendizagem da língua inglesa por meio do seu contato com os jogos digitais.

Registra-se que a opção do uso do formulário eletrônico sofreu determinante influência do cenário social de distanciamento social trazido pela pandemia do COVID-19. Assim, visando obter dados que refletissem a realidade do público de estudantes, mas sem colocar em risco a saúde dos pesquisadores e dos entrevistados, o uso da internet para o envio do questionário foi a melhor opção encontrada para a realização desta pesquisa.

O questionário eletrônico foi construído no Google Forms contendo dez questões. A pesquisa do tipo survey é escolhida quando os pesquisadores desejam interrogar diretamente às pessoas sobre determinado comportamento que está sendo estudado. Desse modo, esse tipo de pesquisa consiste na solicitação de informações a um quantitativo significativo de respondentes sobre a problemática em foco (GIL, 2011). Para Babbie (1999, p. 78), esse tipo de pesquisa caracteriza-se por ser lógica, determinística, geral, parcimoniosa e porque "tipicamente examina uma amostra da população", por meio da aplicação de um questionário estruturado.

Os pesquisadores organizaram a fase de testagem do questionário, sendo este enviado a treze estudantes; nesta fase foi inserida uma pergunta adicional, ao final do documento digital, de maneira que o respondente pudesse indicar críticas para a melhoria do instrumento. Esta fase foi realizada no dia 21 de abril de 2020.

Finalizada a testagem, a versão final do questionário foi concluída no dia 23 de abril e este foi enviado aos sujeitos foco do estudo: estudantes da Educação Básica e do Ensino 
Superior. A estratégia adotada pelos pesquisadores foi conseguir alcançar o máximo possível de aluno, sendo o questionário disseminado principalmente por meio de grupos virtuais em que os seus membros estavam matriculados seja na Educação Básica ou no Ensino Superior; também foi permitido que esses sujeitos compartilhassem o link do questionário com seus colegas que também se encaixassem no perfil do público pesquisado.

Os pesquisadores mantiveram o questionário aberto para acolhimento das respostas no período de 23 de abril a $1^{\circ}$ de maio de 2020 e foram obtidas 117 respostas. Registra-se que o questionário eletrônico foi acessado por 118 pessoas, sendo que 117 delas $(99,1 \%)$ aceitaram participar voluntariamente da pesquisa. Apenas um participante se recusou $(0,9 \%)$ a contribuir. Ao filtrar a planilha e excluir respostas duplicadas de um mesmo respondente, chegou-se a um total de 114 estudantes participantes deste estudo.

Os dados coletados foram analisados conforme as categorias pré-concebidas pelos pesquisadores e que buscam confirmar ou refutar a hipótese de que a rotina dos jogos digitais pode trazer benefícios para o aprendizado do idioma inglês pelos estudantes. A seção abaixo apresenta os resultados encontrados.

\section{Resultados}

A primeira seção do formulário eletrônico buscou caracterizar os respondentes. Assim, a primeira pergunta foi “Qual a sua idade?”. A Figura 1 apresenta o gráfico com os percentuais do público pesquisado, por idade.

Figura 1 - Idade dos estudantes pesquisados

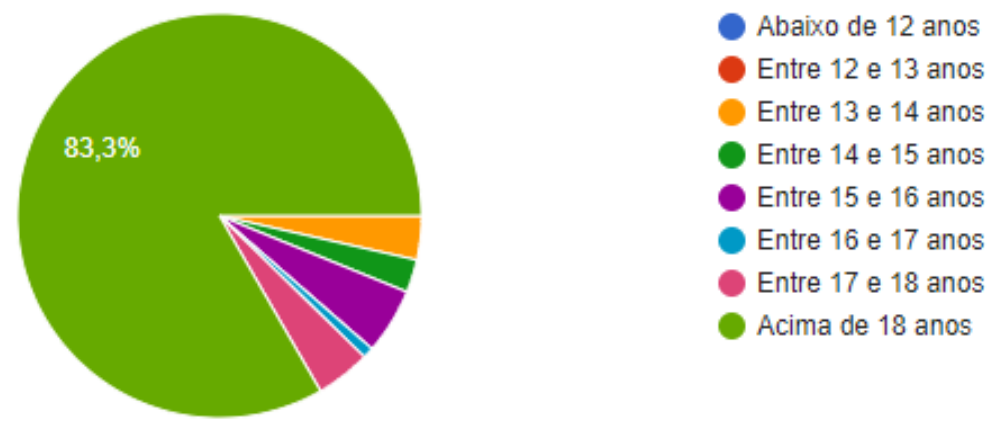

Fonte: Elaborada pelos autores.

Pelo gráfico exposto na Figura 1, observa-se que o maior número de respondentes é composto por estudantes com mais de 18 anos (83,3\%). Logo depois, embora em parcelas bem menores, aparecem estudantes com idade entre 17 e 18 anos (4,4\%), entre 16 e 17 anos (0,9\%), 
entre 15 e $16 \operatorname{anos}(5,3 \%)$, entre 14 e 15 anos (2,6\%), entre 13 e 14 anos (3,5\%). Assim, documenta-se a ausência de entrevistados com idade inferior a 13 anos de idade.

A segunda questão buscava identificar o grau de escolaridade do entrevistado: "Você está matriculado em qual nível de escolaridade?". As respostas estão representadas na Figura 2 abaixo.

Figura 2 - Nível de escolaridade dos estudantes pesquisados

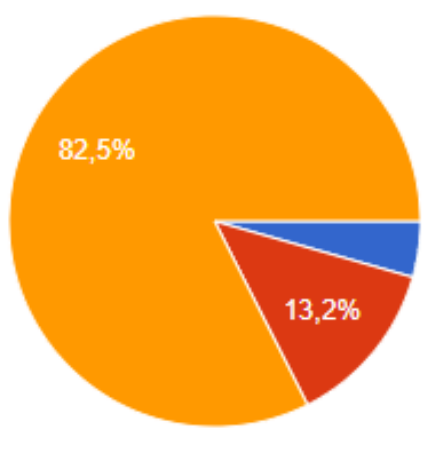

Ensino fundamental (do $6^{\circ}$ ao $9^{\circ}$ ano)

Ensino Médio $\left(1^{\circ}\right.$ ao $3^{\circ}$ ano do Ensino Médio)

Ensino Superior

Fonte: Elaborada pelos autores.

Pela análise da Figura 2, observa-se que a maior parte dos estudantes pesquisados está matriculada em cursos superiores (82,5\%). Aqueles que estão no Ensino Médio representam $13,2 \%$ e o restante, $4,3 \%$, estão matriculados no Ensino Fundamental.

Em seguida, temos uma pergunta delimitadora: "Você tem o hábito de jogar jogos digitais?". Caso o participante respondesse "Sim", ele continuaria a participar da pesquisa, sendo-lhe apresentadas as demais perguntas do questionário. Se a escolha do respondente fosse "Não", o questionário the apresentaria a seção "Enviar formulário". As respostas estão evidenciadas no gráfico da Figura 3.

Figura 3 - Hábito de jogar em jogos digitais

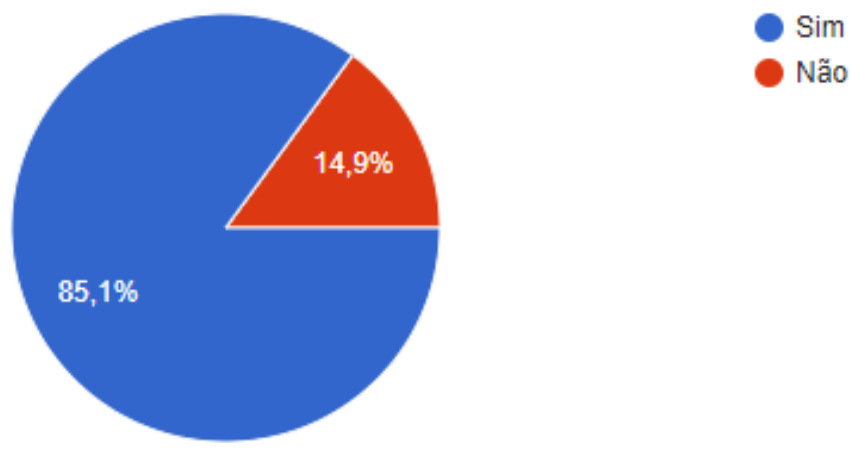

Fonte: Elaborada pelos autores. 
Observa-se que, do total de estudantes entrevistados, 97 deles $(85,1 \%)$ responderam que têm os jogos digitais como um hábito. Conforme já dito, os 17 estudantes $(14,9 \%)$ que disseram que não têm esse hábito tiveram o formulário eletrônico finalizado, sendo-lhes agradecida a sua participação na pesquisa.

A próxima seção foi intitulada como "Os jogos digitais e os impactos no estudo da língua inglesa" e a primeira pergunta foi "Com qual frequência você acessa os jogos digitais?". A Figura 4 apresenta o índice das respostas.

Figura 4 - Frequência no acesso a jogos digitais

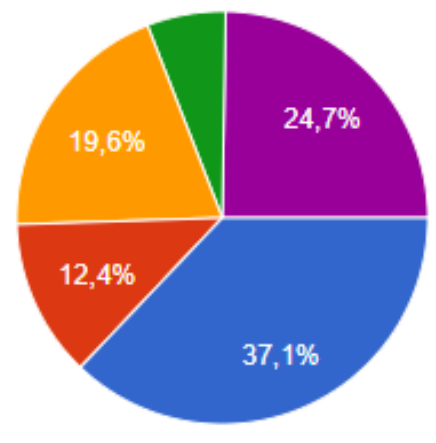

Tenho o hábito de jogar todos os dias.

Normalmente, jogo pelo menos 5 (cinco) vezes na semana.

Normalmente, jogo pelo menos 3 (três) vezes na semana.

Jogo apenas aos finais de semana

Não tenho uma periodicidade de jogo (tem semanas que jogo mais e outras em que jogo menos)

Fonte: Elaborada pelos autores.

Aqui, observa-se que não há mais uma faixa que prevaleça demasiadamente frente às outras. Pela análise do gráfico da Figura 4, percebe-se que pouco mais de um terço dos entrevistados (36 estudantes) disseram ter os jogos digitais como um hábito diário. Outros 24 deles $(24,7 \%)$ disseram que não terem uma periodicidade na prática dos jogos digitais. Uma parcela próxima a um quinto dos entrevistados (19 deles) disse jogar pelo menos três vezes na semana. Aqueles que disseram jogar apenas aos finais de semana representam 6,2\% (6 estudantes), fator que pode estar vinculado ao estabelecimento de uma disciplina necessária ao terem que conciliar os estudos durante e, possivelmente, atividades profissionais e ou de estágio durante a semana.

A próxima pergunta foi incluída para que os pesquisadores coletassem o entendimento dos estudantes sobre o estudo da língua inglesa na Escola. Para isso a pergunta foi "Os jogos digitais, em sua maioria, utilizam a lingua inglesa. Sobre isso, responda:", sendo-lhes apresentadas duas possibilidades: uma primeira que apontava para um estudo em sala de aula que tivesse lhes auxiliado no entendimento do que o jogo lhes apresentava no idioma inglês e uma segunda opção que dizia que o conhecimento obtido em sala de aula teria sido insuficiente para a compreensão dos jogos. A Figura 5 abaixo apresenta o gráfico das respostas coletadas. 
Figura 5 - O aprendizado da língua inglesa em sala de aula e a relação com o entendimento dos comandos dos jogos digitais

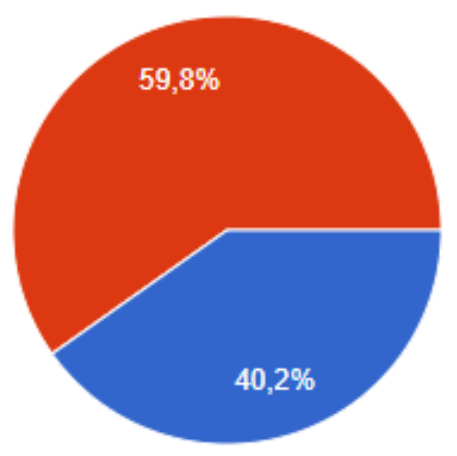

O que eu aprendi nas aulas de Língua Inglesa, na Escola, me ajudaram a entender o jogo.

O que eu aprendi nas aulas de Língua Inglesa, na Escola, não foram suficientes para que eu entendesse 0 jogo.

Fonte: Elaborada pelos autores.

É possível observarmos que a maioria dos alunos (59,8\%) aponta que o aprendizado que obtiveram no ambiente escolar não foram suficientes para o entendimento dos comandos dos jogos digitais. Como já apontava a Figura 4, uma parcela considerável tem o hábito de jogar habitualmente, o que sugere que eles tenham somado aos conhecimentos adquiridos na sala de aula, outros meios de consulta (dicionários físicos, pesquisas na internet, interação com outros jogadores etc.) para poderem se desenvolver nos jogos digitais. A próxima pergunta busca justamente saber sobre esse aprendizado da língua inglesa, mas agora focando no quanto os jogos digitais têm contribuído para isso. A figura abaixo apresenta a organização das respostas enviadas pelos estudantes.

Figura 6 - O aprendizado da língua inglesa no ambiente dos jogos digitais

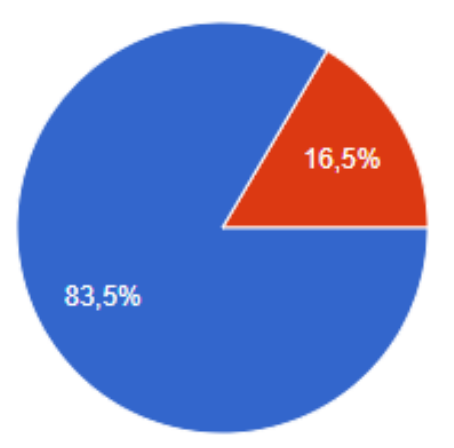

Aprendo muito sobre o idioma inglês no período em que estou jogando.

Aprendo pouco sobre o idioma inglês no período em que estou jogando.

Fonte: Elaborada pelos autores.

O gráfico da Figura 6 é para a questão “A partir da sua experiência com a língua inglesa nos jogos digitais, responda:" e lhe eram oferecidas as duas opções constantes na figura. Dos 97 respondentes, apenas 16 deles $(16,5 \%)$ apontaram que aprendem pouco sobre a língua 
inglesa nos processos do jogo digital. O restante dos entrevistados (81 estudantes) diz aprender muito sobre o idioma inglês ao jogarem no ambiente digital.

A sétima questão do questionário foi incluída pelos pesquisadores com o intuito de identificar se os estudantes, por meio dos jogos digitais, entendiam estar trabalhando as quatro competências da língua inglesa. À pergunta "Quais dos recursos abaixo você usa e interage com a língua inglesa dentro dos jogos digitais?", foi informado ao respondente que ele poderia assinalar mais de uma das questões apresentadas, sendo elas: i) Leitura - Navegação pelos menus, envio de comandos aos personagens, executar comandos de ações etc.; ii) Escrita Conversas em chats e fóruns dentro de jogos on-line que possuam esta opção; iii) Audição Conversas em tempo real em equipes compostas por jogadores de outros países; iv) Fala Respostas às conversas em tempo real com jogadores falantes da língua inglesa; e v) Nenhum dos recursos acima. As respostas dos estudantes estão apresentadas na figura abaixo.

Figura 7 - Habilidades exercitadas pelos estudantes durante os jogos digitais

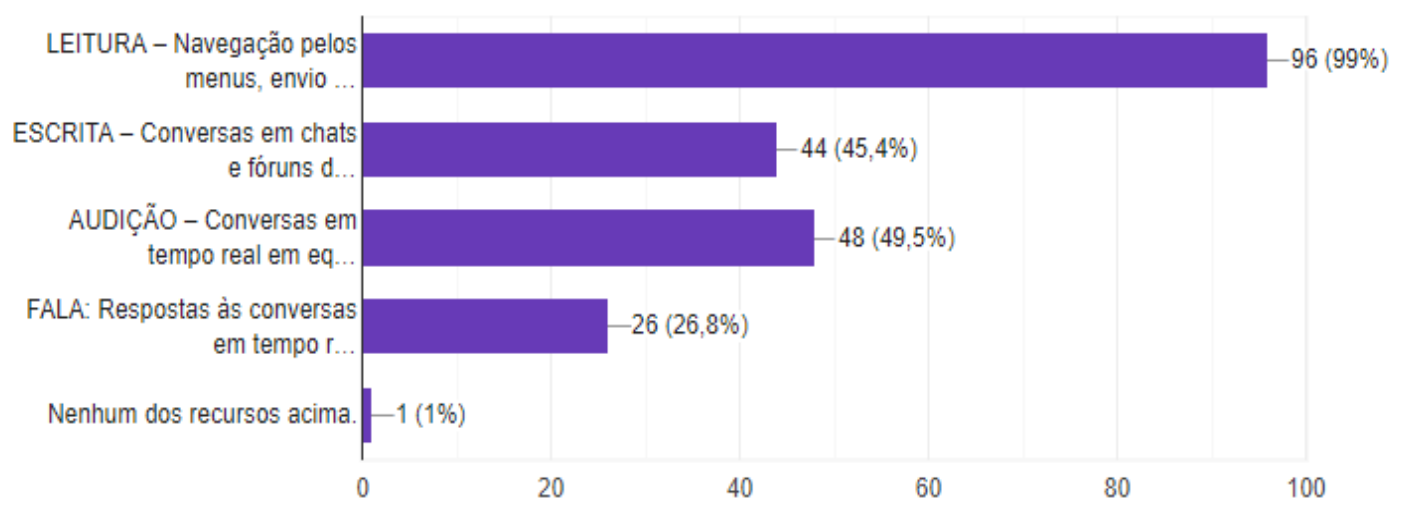

Fonte: Elaborada pelos autores.

Sobre as competências da língua inglesa utilizadas como interação dos estudantes no ambiente dos jogos digitais, a leitura foi aquela que os respondentes alegaram mais utilizar, com 96 marcações $(99,0 \%)$. A audição foi apontada como uma habilidade utilizada durante os jogos digitais, recebendo 48 marcações $(49,5 \%)$, um fator importante, visto que "treinar o ouvido" é importante para o aprendizado de outro idioma. A escrita foi assinalada por 44 estudantes $(45,4 \%)$, dado também importante para a nossa pesquisa. Contudo, menos de um terço deles (26 estudantes) disseram exercitar a fala durante os jogos digitais, fator que aponta que esses jogos não estimulam a verbalização durante os seus processos. Registra-se que apenas um respondente disse não identificar nenhuma das quatro habilidades na prática dos jogos digitais. Outro registro importante é que cada um dos estudantes assinalou, em média, o uso de no mínimo duas destas habilidades durante os seus jogos. 
Para a oitava questão cujo comando foi “Com a sua prática com os jogos digitais, você considera que o seu desempenho na língua inglesa melhorou em quais áreas?", eram apresentadas as seguintes opções: i) Aprendi novos termos da língua inglesa; ii) Aprendi melhor a estrutura da língua inglesa (utilizar melhor os tempos verbais, a ordem das palavras); iii) Aprendi a conversar na língua inglesa, com maior segurança; e iv) Agora consigo entender as regras dos jogos digitais, mesmo estando escritas na língua inglesa. Também para essa questão, o estudante poderia assinalar mais de uma opção. As respostas estão expostas no gráfico abaixo.

Figura 8 - Melhorias no exercício da língua inglesa por meio dos jogos digitais

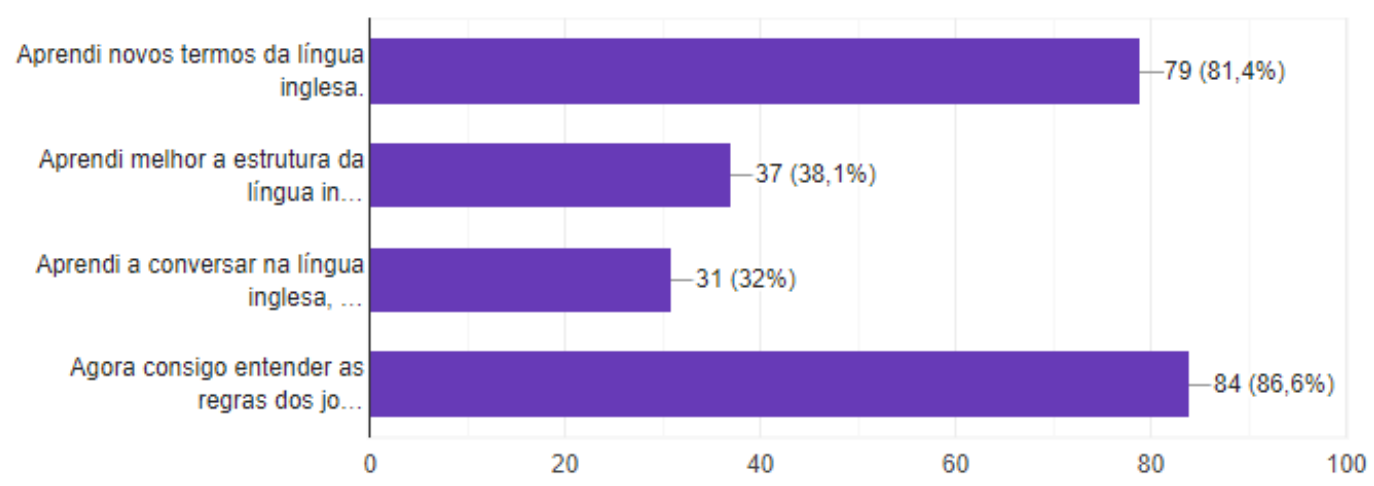

Fonte: Elaborada pelos autores.

Pela análise da Figura 8, ao serem perguntados em quais áreas os estudantes consideravam que tiveram melhorias no seu aprendizado de língua inglesa, 84 deles $(86,6 \%)$ disseram ter melhorado o seu entendimento das regras dos jogos, mesmo estando escritas no idioma inglês. Para 79 deles $(81,4 \%)$, foi possível aprender novos termos da língua inglesa. Para 38,1\% dos respondentes (opção assinalada por 37 estudantes), os jogos digitais compreenderam melhor a estrutura do idioma. Por fim, 31 estudantes (32\%) disseram que ter aprendido a conversar na língua inglesa. Este último dado traz proximidade com os 26 estudantes que disseram desenvolver a fala no idioma inglês durante os jogos (Figura 7).

$\mathrm{Na}$ última pergunta desta segunda seção, o estudante foi questionado "Você acredita que, ao praticar os jogos digitais, você se sente estimulado a aprender outros tipos de conteúdos (culturais, históricos, geográficos etc.)?" e as opções de resposta eram "Sim” ou "Não". As respostas estão organizadas no gráfico abaixo. 
Figura 9 - Estímulo ao aprendizado de outros conteúdos por meio dos jogos digitais

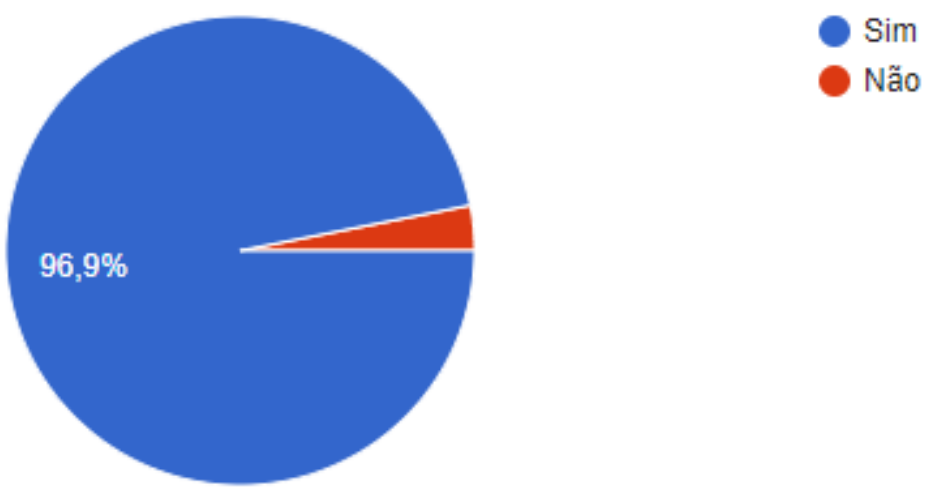

Fonte: Elaborada pelos autores.

A decisão de incluir esta pergunta no questionário deveu-se à hipótese secundária tida pelos pesquisadores de que a também possível ampliação dos conhecimentos do idioma inglês e a segurança em articulá-lo poderiam trazer para o estudante o interesse complementar em pesquisar novos materiais impressos e digitais escritos na língua inglesa que tratassem da cultura, da história, da geografia, dentre outros, que até então (no estágio de pouco conhecedor da língua inglesa) lhe parecia estranhos. Pela análise da Figura 9, os estudantes responderam que, além do conhecimento/aprofundamento no aprendizado da língua inglesa, para a larga maioria deles (96,9\%, ou seja, 94 estudantes) os jogos digitais também os estimulam a buscar outros aprendizados em outros tipos de conteúdo.

Àqueles que assinalaram negativamente a esta questão, a mensagem de encerramento e agradecimento por ter participado da pesquisa lhes foi apresentada. Para os estudantes que assinalaram "Sim", foi-lhes requerido que respondessem uma pergunta adicional. O objetivo desta pergunta foi investigar qual(is) seria(m) este(s) outro(s) conteúdo(s) de interesse e, para isso, perguntou: "Durante os jogos, você já aprendeu ou teve sua curiosidade atiçada por algum destes conteúdos ou temas que lhe trouxeram novas oportunidades de aprendizagem?".

O estudante foi informado de que poderia marcar mais de uma opção, caso assim ele desejasse. As opções eram: i) Devido ao local em que o jogo é ambientado, tive curiosidade sobre "aspectos geográficos" e me senti motivado(a) a pesquisar a respeito (características de um país, tipos diferentes de climas, de terrenos, de vegetação...); ii) Devido ao ambiente do jogo, tive curiosidade sobre "aspectos históricos" e me senti motivado(a) a pesquisar a respeito (civilizações antigas, costumes de diferentes épocas....); iii) Devido aos processos que acontecem no jogo, tive curiosidade sobre "conhecimentos técnicos" e decidi pesquisar mais a respeito (montagem de equipamentos, construções de edificações ou de diversos materiais etc.); 
iv) Devido aos recursos disponíveis no jogo, tive curiosidade sobre "gerenciamento de recursos" e decidi pesquisar mais a respeito (Simuladores de fazendas, cidades, vida doméstica...); e v) Pela forma que o jogo é planejado, fui motivado(a) a estudar mais sobre "aspectos socioculturais" (como interações com outros jogadores ou personagens afetam o curso do enredo do jogo). A Figura 10 apresenta as respostas dos entrevistados.

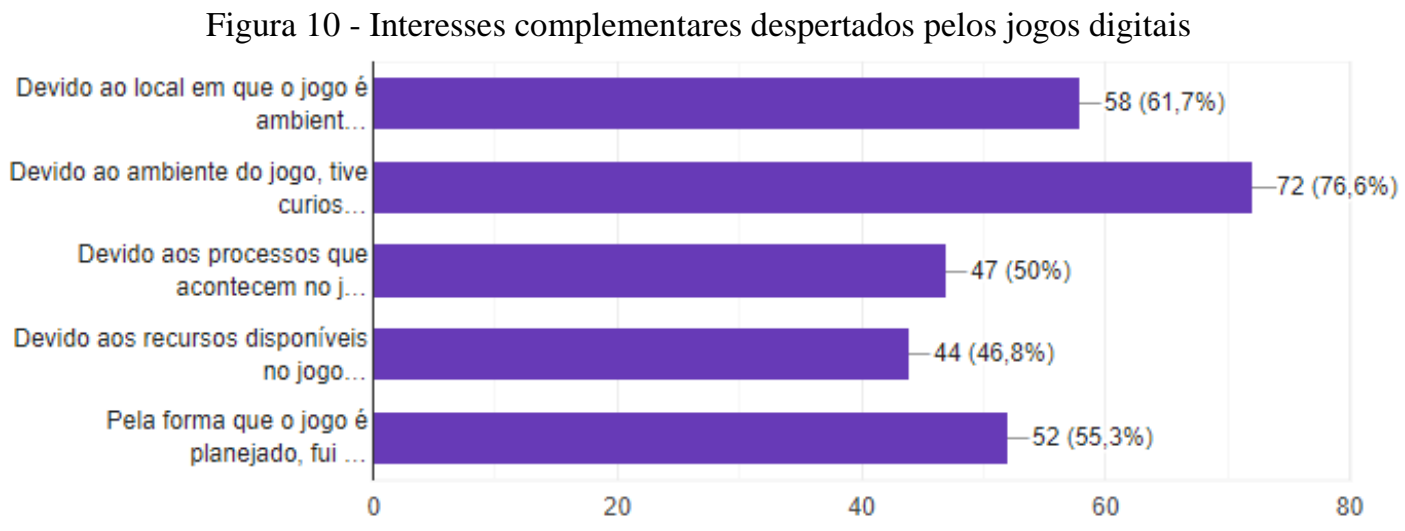

Fonte: Elaborada pelos autores.

Dos 94 estudantes que disseram ter sido incentivados pelos jogos digitais a buscar outros conhecimentos, cada um deles anotou, em média, três opções, o que confirma a hipótese secundária trazida pelos pesquisadores. Os percentuais das marcações demonstram que 76,6\% (72 marcações) dos estudantes se sentiram motivados a buscarem novos conhecimentos ligados a aspectos históricos; 61,7\% (58 marcações) apontaram que tiveram interesse em conhecer um pouco mais sobre aspectos geográficos de outras regiões; $55,3 \%$ (52 marcações) tiveram interesse em aspectos socioculturais; 50,0\% (47 marcações) demonstraram interesse em aprofundarem os seus conhecimentos técnicos; e 46,8\% (44 marcações) dos estudantes disseram que os jogos thes trouxeram o interesse em aprofundar os estudos na área de gerenciamento de recursos. É interessante notar que, em média, os estudantes assinalaram três áreas secundárias de interesse.

\section{ANÁLISE DOS DADOS}

De posse dos dados coletados pelo formulário eletrônico, os pesquisadores começaram a organizá-los. Primeiramente, os dados possibilitaram traçar o perfil dos respondentes. A maioria deles é composto por estudantes com idade superior a 18 anos (Figura l) e cursam o Ensino Superior (Figura 2). Nesta fase, entende-se que o indivíduo já tenha atingido um maior nível de maturidade social e acadêmica; nesta fase, o estudante já tem, em tese, uma visão crítica e reflexiva sobre o seu percurso escolar e sobre o seu processo de aprendizagem. 
Uma expressiva parcela desses estudantes $(85,1 \%)$ afirmou ter o hábito de jogar jogos digitais (Figura 3 ) e quase a metade deles $(49,5 \%)$ afirmam que jogam pelo menos cinco vezes na semana (somadas as parcelas daqueles que afirmam jogar todos os dias e aqueles que disseram jogar cinco vezes na semana), conforme Figura 4. Este dado é importante para a nossa pesquisa, pois tem-se a conclusão de que os estudantes encontram atrativos nos jogos digitais e que, portanto, como são jogos que trazem a língua inglesa como idioma predominante, esses jovens se veem obrigados a entender os comandos escritos neste idioma para que consigam acessá-lo e evoluir nas fases dos jogos. Aqui, podemos dizer que, ao evoluir nas fases dos jogos, o estudante também evolui no aprendizado da língua inglesa. Sendo o jogo um hábito, o estudo do idioma tem sido frequente, potencializando os ganhos no aprendizado do "novo" idioma. Vygotsky ficaria entusiasmado com essa possibilidade!

Um dado importante trazido pela pesquisa é que, para $40 \%$ dos estudantes, o estudo da língua inglesa na Escola foi importante para que ele entendesse os comandos dos jogos (Figura 5). Apesar de ser menor que os outros $60 \%$ que disseram o contrário, entendemos que o ambiente dos jogos digitais possui um vocabulário específico e que não está sendo tratado em sala de aula, mas que, identificado essa possibilidade de aplicação da língua inglesa e tendo-a como prazerosa para o aluno, o professor pode aproveitar-se desse dado para o seu planejamento docente de sala de aula. Os dados apontam que há uma base aprendida em sala de aula, mas que ela precisa ser melhorada, ou seja, o estudo da língua inglesa pode ser mais bem aproveitado se este for ampliado, incluindo-se práticas simulando o ambiente de jogos digitais, por exemplo. Trazer para a sala os principais termos em inglês utilizados no ambiente dos jogos pode tornar as aulas mais prazerosas e participativas para os alunos e, consequentemente, ampliando as possibilidades de aprendizado do idioma inglês.

Complementarmente à discussão anterior, a Figura 6 já sustenta a nossa defesa de necessária conciliação do estudo em sala de aula e as possibilidades positivas trazidas pelos jogos digitais: o gráfico resultante das respostas dos estudantes mostra que 83,5\% (portanto, uma larga maioria) deles aprende muito sobre a língua inglesa durante o tempo em que estão imersos nos jogos digitais. Esta autorreflexão dos estudantes dialoga com a pesquisa realizada por Centenaro (2016) que considera que o uso de jogos digitais no ensino da língua estrangeira pode colaborar para a prática da língua-alvo. Porém, o autor recomenda que os professores de línguas, antes de estabelecer essa proposta de relação "estudo formal x jogos digitais", devem buscar conhecer quais são os jogos e o seu funcionamento, selecionar aqueles que considera 
mais potentes para o conteúdo a ser trabalhado e identificando o melhor desenho metodológico para o seu planejamento de aulas.

Confrontando os dados trazidos pelas figuras 4, 5 e 6 , podemos concluir que o estudante tem o estudo da língua inglesa em sala de aula como básica e insuficiente para o ambiente dos jogos digitais (Figura 5); exposto cotidianamente a comandos, alertas e conversações no ambiente dos jogos digitais (Figura 4), ocorre ampliação do aprendizado na língua inglesa (Figura 6).

Trazendo a discussão sobre os 16,5\% (Figura 6) que acreditam não terem desenvolvido habilidades na língua inglesa, este dado pode estar relacionado com uma estratégia de mercado dos jogos digitais em trazerem versões dubladas ou com legendas em português. O estudo de Gonçalves (2016) aponta para lógica de mercado: a tradução dos jogos para diferentes idiomas. $\mathrm{Se}$ antes os jogos tinham narrativas simples e processos intuitivos, pouco importava os comandos em sua língua original. Contudo, os jogos atuais apresentam cenários mais complexos, semelhantes a um filme; de maneira a ampliar as possibilidades de venda (chegando a indivíduos de diferentes classes sociais e idades), já é possível encontrar esses jogos em versões traduzidas para diferentes línguas, inclusive para a língua portuguesa.

A leitura foi a habilidade mais desenvolvida pelos estudantes durante $o$ ato de jogarem os jogos digitais. Contudo, é importante ressaltar também os ganhos apontados pelos respondentes no desenvolvimento da fala e da audição, dois fatores que são pouquíssimos explorados em sala de aula (LIMA; SOUZA; LUQUETTI, 2014). Os jogos antigos não possuíam muitos diálogos e a maioria das conversas dentro do jogo se davam através de texto. Jogos mais recentes já exploram mais esta prática e, com a ampliação dos jogos on-line, há situações em que os jogadores podem interagir e conversar com outros jogadores em tempo real, fator que pode ter contribuído para que não somente a leitura fosse apontada como habilidade desenvolvida (apesar de ser a mais assinalada), mas também a escrita, fala e a audição, conforme Figura 7.

A aprendizagem tangencial (BREUER; BENTE, 2010; LEITE, 2015) da língua inglesa no ambiente dos jogos pode ser claramente identificada pelas respostas dadas pelos estudantes à oitava pergunta do questionário (Figura 8). Pela análise do gráfico, expõe-se o quanto o ambiente dos jogos digitais pode trazer ganhos na aprendizagem da língua inglesa. $O$ estudo do idioma inglês não é o foco do jogo, mas o jogador se vê estimulado a aprender os comandos e legendas nesse idioma para que consiga obter bons resultados e evoluir em suas fases. As respostas dadas pelos estudantes corroboram com os autores. 
Outro ponto importante para a nossa discussão diz respeito aos ganhos no arcabouço cultural dos estudantes a partir dos ganhos de aprendizado na língua inglesa. Por ser um idioma utilizado em sites (sejam originariamente de países da língua inglesa ou como opção de tradução), os estudantes afirmaram que o ambiente dos jogos aumentou o aprendizado da língua inglesa e que isso incentivou-os a buscar outros conhecimentos (Figura 10). Essa constatação abre possibilidades para os professores desenvolverem projetos multi e interdisciplinares que envolvam os colegas docentes das áreas de História, Geografia, Filosofia, Sociologia, dentre outros. Como exemplo, a série Assasins Creed, que retrata períodos e civilizações históricas com imensa precisão, poderia ser utilizada para explorar ainda mais esses novos cenários, trazendo novas possibilidades de aprendizagem significativa no ambiente escolar.

\section{CONSIDERAÇÕES FINAIS}

As respostas dadas pelos estudantes nos permitem concluir que o ambiente dos jogos digitais apresenta reais possibilidades de aprendizado, especialmente para a Língua Inglesa, confirmando a hipótese inicial desta pesquisa. Concluímos, adicionalmente, que a ampliação do aprendizado nesse idioma abre novas oportunidades de aprendizado para os estudantes; em consequência, abre-se também para o professor de Língua Inglesa a possibilidade de dinamizar a sua prática docente, podendo incluir no seu planejamento termos utilizados no ambiente dos jogos e a proposição de projetos inter e multidisciplinares com outras disciplinas.

Este estudo não descarta e, pelo contrário, estabelece a Escola como um importante ambiente de aprendizado da Língua Inglesa. Identificado o ambiente dos jogos digitais como uma rotina dos estudantes, interessou-nos buscar evidências da possível utilização desse hobby para o aprendizado do idioma inglês. Parecia-nos evidente a ideia de que, tendo sido inserido em um ambiente no qual o idioma predominante é a Língua Inglesa, tendo se mantido nele e tendo feito deste um hábito cotidiano, foi exigido desse estudante aprender/desenvolver o idioma que ali se exercita.

Os dados desta pesquisa demonstram que há aprendizados (no plural!) no ambiente dos jogos digitais e que, se houver o interesse e capacitação dos professores, a mesclagem entre jogos digitais e o estudo formal da Língua Inglesa em sala de aula pode render um processo efetivo de aprendizagem.

É necessário desmistificar, especialmente no ambiente escolar, a ideia de que os jogos digitais seriam apenas recursos voltados à distração e se constituiriam como potencializadores de violência juvenil. Ao tratarmos os jogos digitais como potentes ferramentas auxiliares no 
processo de ensino-aprendizagem, não nos afastamos da necessária atenção que deve ser dada às indicações de faixas etárias recomendadas e expressas no material de divulgação dos jogos. A decisão pela inclusão e qual o jogo que será trazido para o ambiente da sala de aula caberá ao professor. Tomados esses devidos cuidados, este estudo apresenta os jogos digitais como potentes contribuidores na busca de uma prática pedagógica atrativa e eficaz, especialmente para o estudo da Língua Inglesa.

\section{REFERÊNCIAS}

BABBIE, Earl. Métodos de pesquisas de survey. Belo Horizonte: UFMG, 1999.

BREUER, Johannes; BENTE, Gary. Why so serious? On the Relation of Serious Games and Learning. Journal for Computer Game Culture, v. 4, n. 1, p. 7-24, 2010.

BRINCHER, Sandro; SILVA, Fernando da. Jogos digitais como ferramenta de ensino: reflexões iniciais. outra travessia, Florianópolis, p. 42-69, set. 2012. ISSN 2176-8552. Disponível em: http://periodicos.ufsc.br/index.php/Outra/article/view/21768552.2011nesp1p42. Acesso em: 17 mai. 2020.

CENTENARO, Franciele Knebel. Investigação de uma abordagem pedagógica para o ensino de língua inglesa por meio de jogos digitais. Dissertação (Mestrado em Tecnologias Educacionais em Rede) - Universidade Federal de Santa Maria, 2016. Disponível em: http://repositorio.ufsm.br/bitstream/handle/1/10683/CENTENARO\%2c\%20FRANCIELE\%2 0KNEBEL.pdf? sequence=1\&isAllowed=y. Acesso em 20 mai. 2020.

CONNOLLY, Thomas, BOYLE, Elizabeth, MACARTHUR, Ewan, HAINEY, Thomas; BOYLE, James. A systematic literature review of empirical evidence on computer games and serious games. Computers \& Education, 59 (2012), 661-686. Disponível em: https://www.learntechlib.org/p/167558/. Acesso em 17 mai. 2020.

FLEURY, Afonso; NAKANO, Davi Noboru; CORDEIRO, José Henrique Dell'Osso. Mapeamento da indústria brasileira e global de jogos digitais. [S.1: s.n.], 2014.

GIL, Antônio Carlos. Metodologia do ensino superior. 4. ed. São Paulo: Atlas, 2011.

GONÇALVES, Larissa Magalhães de Almeida. Dante's Inferno: localização e legendagem em jogos digitais. 2016. 179 f., il. Trabalho de conclusão de curso (Bacharelado em Letras Tradução - Inglês). Universidade de Brasília, Brasília, 2016. Disponível em: http://www.bdm.unb.br/bitstream/10483/17229/1/2016_LarissaMagalhaesGoncalves_tcc.pdf. Acesso em 17 mai. 2020.

KOSTER, Raph. A Theory of Fun for Game Design. Paraglyph Press. Scottsdale, Arizona USA, 2005.

LEITE, Bruno Silva. Tecnologias no ensino de química: teoria e prática na formação docente. Curitiba: Appris, 2015. 
LIMA, Lais Teixeira.; SOUZA, Sonia Maria de Fonseca; LUQUETTI, Eliana Crispim França. O ensino da habilidade oral da língua inglesa nas escolas públicas. Círculo Fluminense de Estudos Filológicos e Linguísticos. Volume 13, nº 10. 2014.

PENICHEIRO, Filipe. Fora de jogo: compreensão histórica e jogos digitais. Disponível em: http://estudogeral.sib.uc.pt/handle/10316/44888. Acesso em 17 mai. 2020.

SMOLKA, Ana Luiza. Bustamante, GÓES, Maria Cecília Rafael de. A constituição do sujeito: uma questão recorrente? In: WERTSCH, James V.; DEL RÍO, Pablo; ALVAREZ, Amélia. Estudos socioculturais da mente. Porto Alegre: Artmed, 1998.

VYGOTSKI, Lev Semiónovich. (1934) Pensamiento y lenguaje. In: Obras escogidas, tomo II. Madri: MEC/Visor, 1993, p. 9-348.

Recebido em: 6 de junho de 2020 .

Aprovado em: 21 de julho de 2020. 